\title{
La opulencia en la escasez. Intercambios de objetos, relaciones sociales y ambigüedades en institutos correccionales de Córdoba
}

\section{RMA}

Antropología Social
Graciela María Tedesco

CONICET, Museo de Antropología, Facultad de Filosofía y Humanidades, Universidad Nacional de Córdoba. E-mail: gratedesco@yahoo.com.ar

\begin{abstract}
Resumen
Este artículo se propone reflexionar sobre las relaciones sociales que se entrelazan durante el proceso de dar, recibir, intercambiar distintos objetos en institutos correccionales de la ciudad de Córdoba. A través del análisis de situaciones como "la visita", "el arreglo de las habitaciones", "el fumar y compartir en el sector"; se analizan formas de tejer vínculos con el afuera, actualizar recuerdos sobre la calle, y de producir intercambios y reforzar ciertos valores dentro del grupo que convive en el instituto. La descripción de estas situaciones implica asimismo, indagar los mecanismos y circuitos a través de los cuales se incorporan distintos sentidos a los objetos, así como también, el modo en que éstos configuran la subjetividad de las personas. De esta manera, el artículo busca mostrar la dinámica que lleva a que, en contextos institucionales marcados por privación y escasez, los jóvenes generen diversos intercambios y utilicen la ambigüedad como un medio para un construir abundancia y poder.
\end{abstract}

Palabras clave: jóvenes, institutos correccionales, relaciones sociales, objetos

Opulence on scarcity. Exchange of objects, social relations and ambiguities in correctional institutes of Córdoba.

\begin{abstract}
This article proposes to reflect on the social relations that are intertwined in the process of giving, receiving, exchanging various objects in correctional institutes in the city of Córdoba. Across the analysis of situations as "the visit", "the arrangement of the bedroom", "to smoke and share in the sector"; discusses ways to weave ties to the outside, upgrade memory on the street and produce exchanges and strengthen certain values within the group that lives in institute. The description of these situations also means, investigate the mechanisms and circuits through which incorporate different meanings to objects, and also, they shape the subjectivity of people. Thus, the article shows the dynamics means that, in institutional contexts marked by deprivation and scarcity, young men exchanges and use the ambiguity, as a way for one to construct abundance and power.
\end{abstract}

Keywords: young people, correctional institutes, social relationships, objects.

Entre fines del 2003 y comienzos del 2006 realicé trabajo de campo en dos institutos correccionales dependientes de la "Subsecretaría de Atención Integral del Niño y el Adolescente en Conflicto con la Ley Penal"1 para mi tesis de Maestría en Antropología. La misma buscó analizar las experiencias de algunos jóvenes que se encuentran en el Sistema Correccional de Córdoba y explorar los sentidos que le dan a las violencias en el marco de sus relaciones sociales ${ }^{2}$. En este sentido, fue necesario observar las rela-

\footnotetext{
1 El acceso al campo de la investigación se produjo luego de un pedido formal escrito de autorización, una entrevista personal con la directora de la Subsecretaría y la intermediación de una persona que había conocido poco tiempo antes en otra dependencia de la Subsecretaría. Durante el artículo utilizaré comillas para destacar palabras relativas al ámbito de la investigación; la letra cursiva será empleada para los términos pertenecientes al grupo investigado; y las comillas y cursivas se usarán en la trascripción de fragmentos de notas de campo o de entrevistas.

2 Se consideró en este trabajo que estudiar juventud no implica definir quién es joven y quién no lo es, sino analizar el proceso mediante el cual se designa a los individuos socialmente como tales.
}

ciones que se tejen en el instituto, así como también, las que se mantienen con la familia, los amigos y conocidos en el afuera o la calle .

El presente artículo pretende reflexionar sobre los lazos sociales que se configuran durante el recorrido de algunos objetos que llegan, circulan y salen del instituto. A partir del trabajo de campo mencionado ${ }^{4}$, exploro a conti-

3 Si bien la calle es utilizada para nombrar aquello que está por fuera del instituto, constituye al mismo tiempo una noción relativa. Cuando los chicos están en el instituto, la casa/familia forma parte de la calle, con un sentido positivo ligado a los afectos cercanos y a las cosas que les gusta hacer. Sin embargo, cuando se está fuera del instituto, la calle suele ser pensada en oposición a la casa, y pasa a ser identificada con aquellas cosas que se hacen con gente conocida, como el salir y divertirse, fumar, bardear; en lugares habituales como la esquina, la plaza, el centro.

4 Los institutos correccionales que visité están destinados a varones de 16 a 18 años. El instituto Castelli de régimen semi-abierto (mediana seguridad) y el instituto Malvinas es de de régimen cerrado (máxima seguridad). En este artículo los nombres de las instituciones y de las 
nuación el intercambio de objetos durante el momento de la visita y el vínculo que se establece entre quienes los dan y reciben. Se analiza asimismo los circuitos que atraviesan ciertos objetos clasificados como "permitidos" o "prohibidos"; y aquellas cosas que se guardan en las piezas para recordar los afectos y construir identidades. Por último, observo intercambios en el sector ${ }^{5}$ que buscan revertir la carencia de objetos y reforzar valores como la generosidad, la igualdad, la ayuda mutua, dentro del grupo de jóvenes en el instituto.

Prendas de vestir, comida, encendedores, fotos, cartas, rosarios, estampitas, tabaco, marihuana, no son pensados aquí como objetos materiales externos a las personas o con usos y fines únicamente prácticos. Por el contrario, ellos implican modos de construir nuestra subjetividad individual y colectiva (Kopytoff, 1991[1986]), de configurar relaciones sociales y actualizar memorias. Tal como mostró etnográficamente Malinowski (2001[1922]), los intercambios de objetos ponen en evidencia normas tradicionales que regulan modos de tejer relaciones, de clasificar a los demás y de recordar. En este sentido, no constituyen sólo un proceso material, sino una actividad social ligada a los sentidos del grupo (Morton, 2007). A partir de esto, se indagará a continuación las implicancias de sentido que tienen los objetos que circulan en el instituto, así como también, los lazos sociales que se configuran a partir de los mismos.

\section{La visita. Cosas que se traen y se llevan del instituto}

La primera vez que ingresé al instituto Castelli me llamó la atención una hoja pegada en la pared muy cerca de la puerta de entrada, donde se enumeraban aquellas cosas que no podían ingresarse: "alfajores, chocolate, caramelos rellenos, galletas rellenas, magdalenas, chicles, turrón". Al final de la hoja se especificaba que los cigarrillos debían encontrarse en etiquetas nuevas y sin abrir, al igual que los envases de galletas, caramelos y gaseosas. Cuando le pregunté a la persona que me abrió la puerta a qué se debía eso, me respondió que era "porque pueden poner adentro sustancias, drogas, o el chocolate cuando se lo funde se lo puede mezclar con algo, usted sabe" (nota de campo, octubre de 2003). De este modo, el listado se encuentra a la vista de quienes ingresan al instituto y en particular, de aquellas personas que llegan los días de visita.

Los días de visita se producen dos veces por semana en el horario de la siesta. En la puerta del establecimiento se pide el DNI (Documento Nacional de Identidad) a las personas que forman fila afuera y un guardia verifica que el nombre se encuentre en la lista de personas autorizadas por el juez a visitar. Constatado esto, pasan en pequeños grupos y esperan a que se les realice la

personas han sido modificados para preservar la privacidad de las mismas.

5 Espacio cerrado dentro del instituto en el que viven los jóvenes. requisa o inspección de los objetos que traen. Luego, una mujer policía revisa el cuerpo de las visitantes femeninas y un guardia el de los hombres, a fin de evitar que traigan objetos no autorizados (drogas, encendedores, objetos cortantes) que puedan ser pasados a los jóvenes ante el descuido del personal de la institución. La requisa luego se extiende a los jóvenes, quienes al culminar la visita y antes de entrar al sector, son revisados nuevamente.

La sala de visita en el instituto Castelli se encuentra en el ingreso del establecimiento y mide aproximadamente 5 por 7 mts. Este espacio se transforma en sala de visita los días miércoles y sábados por la tarde, cuando se distribuyen sillas blancas de plástico en toda la sala. En una esquina de la habitación hay una escultura de la virgen María de cuyas manos cuelgan decenas de rosarios, que son colocados allí por las madres y abuelas que van a la visita. El instituto Malvinas por su lado tiene dos salas de visita, ubicadas en la parte delantera del establecimiento. Miden alrededor de 4 por $6 \mathrm{mts}$ cada una y en sus paredes hay pinturas de paisajes con árboles y montañas en tonos de verde y marrón, realizados años atrás por un grupo de internos y un profesor. Las salas tienen bancos de cemento pegados a las paredes, que son complementados por sillas de plástico los días de visita.

Como pude observar en algunas oportunidades, en el momento de la visita los chicos presentan un aspecto muy distinto al que tienen cotidianamente en el instituto. Si bien están casi siempre atentos a su presentación personal ${ }^{6}$, los días de visita "se producen" de manera especial. Utilizan en ese momento la muda de ropa y el calzado más nuevo, y humedecen y peinan su cabello prolijamente. Por otra parte, los familiares y amigos también usan ropa arreglada y las mujeres suelen estar maquilladas y algunas con tacos altos. Los niños ocupan un lugar especial, vistiendo hermosos conjuntos de ropa que los destacan por sobre el resto de la visita. La presentación personal es utilizada así para comunicar al otro su aprecio y afecto. Durante el momento de la visita, que dura aproximadamente una hora, cada joven se sienta en círculo con las personas que lo vinieron a ver y allí conversan, fuman, intercambian noticias y regalos, consumen gaseosas y algo de comer; conmemorando de esta manera el reencuentro.

Como se advierte fácilmente al mirar al grupo de la visita, quienes asisten con mayor frecuencia al instituto son las familiares mujeres. Madres, abuelas, tías, hermanas, parejas con sus hijos pequeños, predominan ampliamente entre los visitantes. Asimismo, las madres son, según los chicos, las que "nunca faltan a las visitas"7.

\footnotetext{
6 En general se bañan varias veces al día, cambian de ropa apenas se ensucia, les gusta oler bien y quienes salen de permiso de fin de semana suelen hacerse cortes de pelo a la moda.

7 Cabe señalar aquí que en muchas oportunidades los jóvenes utilizan la palabra madre para identificar tanto a la madre biológica, como a la abuela que los crió. Asimismo, algunos indican que tienen "dos madres": su mamá y su abuela.
} 
"Las madres, siempre están las madres. Primero la madre, después empiezan a caer los hermanos, todos". (Felipe, febrero de 2006, instituto Malvinas)

Las madres (y abuelas) suelen llevar a sus hijos elementos necesarios para la vida diaria en el sector: cigarrillos, artículos de higiene personal, galletas, caramelos, y en algunas ocasiones, tarjetas telefónicas, ropa y calzado. Ellas regalan además, objetos religiosos como estampitas, rosarios, crucifijos que son colocados en las piezas. Asimismo, como narraron algunos jóvenes, las madres se ocupan de llevar el "rancho" a la comisaría cuando recién caen detenidos, es decir, la comida casera y ropa limpia diaria que los haría sentir más cerca de sus casas. Por este motivo, resulta importante para ellos que los sitios de detención no sean distantes o de difícil acceso desde lugar donde viven sus familias. Por otra parte se advierte que la madre actúa como intermediaria en el traslado de cartas, fotos, regalos que comunican al joven institucionalizado con los parientes y amigos que no pueden ir a visitarlo. Ellas además, son quienes persisten en el seguimiento de la situación legal de sus hijos en tribunales. A partir de estas cuestiones, los jóvenes señalan que a las madres se las respeta y se las ayuda, dado que ellas "nunca te abandonan". En algunos casos el padre y/o abuelo puede ocupar un lugar similar al de la madre, pero esto es poco frecuente, ya que la figura paterna es más débil que la materna que cumple múltiples funciones en el hogar y "siempre está".

Los familiares más jóvenes eligen llevar otros objetos al instituto. Hermanas, hermanos, primos autorizados a visitar, regalan a los jóvenes preferentemente dibujos, cartas, poemas, letras de canciones, fotos. También aportan revistas y CDs de música para que se entretengan, y son quienes brindan noticias sobre lo que hacen los amigos, novia, conocidos para mantenerlos informados de lo que ocurre en "la calle".

Las novias de los jóvenes suelen enviarles cartas a través de los familiares que van a la visita. Si bien sólo algunas a quienes los unen vínculos amorosos duraderos solicitan la autorización para visitar, no es común que vayan al instituto. Esto cambia sin embargo, cuando tienen un/a hijo/a en común ya que comienzan a visitarlos con frecuencia junto a éste. Asimismo, son las encargadas de llevar fotos del hijo/a, sobre todo cuando el tiempo de detención se prolonga indeterminadamente.

Por su parte, son pocos los amigos que logran conseguir la autorización del juez o el asentimiento de la familia para visitar en el instituto, dado que muchas veces son considerados "malas" juntas ${ }^{8}$ y se prefiere que mantengan cierta distancia. A raíz de esto quienes están en el instituto no reclaman la presencia física de los amigos,

8 Grupo de personas conocidas, predominantemente de edad similar, con quienes se comparte tiempo, actividades y lugares comunes. sino en cambio, que les envíen algunas cosas a través de sus familiares: "No digo que me vengan a ver sino que aunque sea le alcancen una etiqueta de cigarrillos a mi mamá para que me traiga" (Danilo, diciembre de 2005, inst. Malvinas). Se considera en este sentido, que quienes están afuera tienen mayores posibilidades de conseguir cosas y acceder a diversos bienes, por lo que deben compartirlos con quienes están en el instituto. Este hecho, además de aliviar el "gasto" que la familia asume semana tras semana, posibilita que la amistad perdure a pesar del encierro y la distancia.

Los jóvenes suelen estar pendientes de quiénes tienen visitas con frecuencia y quiénes no. Algunos expresan con orgullo el hecho de ser visitados todas las semanas, mientras que otros reconocen que sus visitas son escasas, justificando esta ausencia en razones económicas o de distancia (especialmente cuando los familiares viven en el interior provincial). La falta de visitas redundará en la escasez de objetos necesarios para la vida cotidiana en el instituto, pero también y más importante, de demostraciones de afecto, de apoyo y recuerdo a pesar de la ausencia.

A partir de esto, los jóvenes también poseen medios para demostrar su afecto y reforzar sus vínculos con el afuera, pasando largas horas de la semana en la fabricación de diversas cosas que obsequian los días de visita.

"Un día, luego de salir del instituto Malvinas tomé el colectivo para regresar a mi casa. El colectivo pasó por frente de otro de instituto que se encuentra en el mismo complejo y se detuvo. Comenzaron a subir entonces personas que habian estado de visita. Al final subió una señora que tenía en sus brazos un barco inmenso hecho con palitos de helado. Además de su tamaño, el barco dejaba ver un gran detalle en su confección. Estaba todo pintado, tenía mástiles con sus velas desplegadas y hasta algunos hombrecitos en distintos lugares de la proa. Mientras se sonreía e intentaba avanzar por el pasillo del colectivo, le dijo a otra persona que se lo había hecho su hijo en el instituto. Finalmente tuvo que ubicarse en los asientos del fondo del colectivo ya que en los otros asientos no cabía con su barco". (Nota de campo, inst. Malvinas, julio de 2005).

Como muestra esta nota, en la salida de la visita es común ver personas que llevan entre sus manos cosas regaladas por los jóvenes. Los objetos que ellos obsequian son realizados con materiales aportados por los docentes o los familiares, como papeles de colores, plasticolas, revistas, yeso, arcilla, palitos de helado. Fabrican así portarretratos, barcos, helicópteros, fuentes, yerberas, ceniceros con palitos de helado; vasijas, jarrones y adornos con arcilla; pósters, dibujos y collages diversos, y 
en algunas ocasiones he observado que realizan pinturas de la virgen María o Jesús para sus madres. De esta manera, fabrican cosas que al ser llevadas a sus casas les permiten estar presentes en las mismas. Por otra parte los regalos que se suelen dar a los hermanos y hermanas, son principalmente dibujos y poemas copiados con gran precisión de revistas o tarjetas. Algunos de estos obsequios se destinan a personas que no ven desde hace tiempo, a quienes mediante las visitas se les hace llegar un recuerdo. De esta manera, los presentes reúnen sentimientos ligados a la familia y la amistad, ayudan a los jóvenes a reconocerse como personas queridas, y generan un ida y vuelta continuo que renueva los lazos de estima que la distancia y la ausencia podrían llegar a debilitar.

\section{Ingresos permitidos y prohibidos}

Desde la lógica institucional, los objetos que ingresan al sector son "permitidos" o "prohibidos" según sus recorridos, lugares en los que se guardan y modos en que se consumen. En este sentido, los significados de las cosas están inscritos en sus formas, usos y trayectorias (Appadurai, 1991[1986]). Son "permitidos" aquellos objetos que la guardia puede ver, revisar y autorizar, y que cumplen con los requisitos que establece la institución (estar en envases cerrados, no tener relleno, etc.). Las cosas permitidas ingresan al instituto a través de un canal lícito asociado a la visibilidad y a lo aprobado en la requisa. Por su parte, los objetos considerados "prohibidos" realizan otros recorridos e implican formas de ocultamiento y disimulo, por ejemplo entre otros elementos que sí son autorizados por el instituto (comida, ropa, etc.).

"Lo pasaban en el desodorante a bolilla, y un día se zarparon y le pusieron todo porro adentro, y cuando lo movieron dijeron, nooo!, lo destaparon, una baranda a marihuana. Y desde ahí no dejaron pasar más desodorante. Ahora solo dejan pasar ese Odorono en crema" (Diego, septiembre de 2005, charla a la salida de la escuela de la Subsecretaría)

Luego de varias charlas y a partir de una confianza construida progresivamente, Diego me explicó como surge de este fragmento, por qué ya no se permite ingresar elementos de higiene personal al instituto como desodorante, champú, pasta dental. Cuando pregunté por esta cuestión al personal de la institución, dijeron que se debía a que muchos de los envases servían para trasladar sustancias (drogas), y que por otra parte, se intentaba aliviar el gasto de las familias que muchas veces no podían comprar esas cosas. Los jóvenes sin embargo, manifestaban su descreimiento sobre esta última razón y se quejaban de que los productos que se proveían ahora eran escasos y de mala calidad. Si tenemos en cuenta que las cosas que reciben de sus familias representan en gran medida una muestra de afecto y de recuerdo, no es difícil comprender entonces los cuestionamientos que se producen ante cada objeto que se prohíbe ingresar.

Los encendedores son otro de los objetos que se prohíben tener en el sector. Los jóvenes deben solicitar entonces fuego a la guardia para prender sus cigarrillos. Aún cuando esto ocurra innumerables veces, son múltiples las formas con las que se evita depender del encendedor de la guardia. En este sentido, los encendedores llegan al sector adoptando un camino disimulado o "desviado" del que tienen las cosas autorizadas. A este respecto se puede pensar junto con Appadurai (1991: 37 [1986]) que en la construcción recíproca del valor, no sólo las rutas desempeñan un papel importante, sino también las desviaciones que son significativas en relación a los recorridos respecto de los cuales se apartan. De este modo, objetos como un encendedor pasan a ser prohibidos porque "desvían" su trayectoria, recorren caminos que no deberían atravesar y llegan a poder de los jóvenes. En relación a este tipo de objetos, una entrevista realizada a Felipe me señaló algunas cuestiones ordenadoras de las reglas que se comparten en el sector:

Felipe: - (...) Ya si fueran preguntas más íntimas no te contesto.

G: - ¿Cómo qué?

Felipe: - Preguntas así más internas de acá. Como por ejemplo qué es lo que hacen en el sector, qué saben guardar. No sé, no sé, no te entiendo esas preguntas (Felipe, marzo de 2006, Inst. Malvinas).

Se observa aquí que las cosas "más intimas" y actividades "internas" del sector son resguardadas a partir del secreto y el silencio. Esto constituye un capital que otorga autonomía a los jóvenes y los protege de la privación continua que impone la institución. Por otra parte, cuando objetos como el encendedor se logran ingresar, éstos se prestan y comparten. En relación a esto, tirar la paloma es una práctica relatada por los jóvenes que implica usar colectivamente un encendedor y transgredir el encierro (enyugue $e^{9}$ impuesto en las piezas. Una paloma es un trapo en el que se envuelve un encendedor, al que se ata a un hilo largo para poder tirarlo a la pieza de al lado y luego regresarlo a la habitación de donde salió. A la paloma entonces se ata la posibilidad de fumar, pero a su vez, la de ser castigados si resultan descubiertos. Los cigarrillos de marihuana (llamados también porros, fazos, caños, chalas) son otra cosa que los jóvenes comparten cuando llegan a sus manos.

"Estábamos en el comedor y en un momento
Jeremías, Agustín y Juan salieron y fueron al
baño. Seguimos mirando la película, y al ratito
vino Agustín, bastante agitado. Se lo notaba
nervioso y miraba hacia afuera en dirección a los
baños. Alcancé a oler marihuana y deduje que

9 Modo en que los internos llaman al encierro obligatorio que se produce en las piezas durante la siesta y la noche. 
la habian fumado en el baño. Agustín escupía constantemente y abría la boca. -"¿Tengo olor?" le preguntaba a Alejandro y se acercaba para que lo oliera. Contagiados por su nerviosismo, todos mirábamos hacia afuera hasta que en un momento, se abrió la reja del enlace y entraron tres guardias y el jefe de contención. Caminaron hasta el baño y dos de ellos entraron. -"Nos batieron la cana" murmuró Agustín. Minutos después fueron saliendo del baño Juan, Jeremías y otro chico caminaron con las manos en la espalda y la cabeza baja. Sin decir nada, fueron hasta la reja escoltados por los guardias y atravesaron la puerta. Uno de los guardias se arrimó al comedor y llamó a un chico que estaba sentado en el banco cerca de donde nos hallábamos nosotros. Parece que también había estado fumando, porque se levantó callado y se unió al grupo de chicos descubiertos, que se dirigía hacia el "aislado"10. (Nota de campo, instituto Castelli, septiembre de 2005)

Durante el trabajo de campo se hizo costumbre que cuando yo llegaba al instituto para realizar alguna actividad, los guardias me mostraran una lista en la que me indicaban quienes estaban aislados y por tanto "no podían salir". Entre los motivos más frecuentes para estar aislado se encontraban el haber faltado el respeto a un guardia, haber peleado con otro interno, haber sido descubiertos fumando marihuana. La marihuana en el instituto tiene una doble prohibición, además de ser una sustancia ilícita e ingresada por canales ocultos, se fuma de forma secreta en lugares como los baños y piezas. Convidar un fazo es un gesto que demuestra la generosidad de alguien que se arriesgó a ingresarlo en el sector y al mismo tiempo, la complicidad de los otros que se comprometen a compartir la sanción si resultan descubiertos. En este sentido, es signo de apoyo mutuo y de compartir la misma situación ${ }^{11}$. Rebasando las distancias, tal como para los Trobriandeses se afrontan peligros de muerte al navegar por extensos mares en pequeñas canoas para intercambiar collares y brazaletes y obtener así amigos accesibles en las cercanías y aliados en las regiones lejanas; para los jóvenes que se encuentran en institutos bien vale la pena arriesgarse a "fumar un caño" y recibir una sanción, si con ello pueden producir espacios de autonomía, estrechar vínculos, generar alianzas y resignificar el poder. De este modo, el ingreso de elementos prohibidos conlleva también el compartir las consecuencias de la trasgresión.

\footnotetext{
10 Habitación que se encuentra en el instituto separada de las piezas comunes, donde se encierra al joven para cumplir con una sanción. El nombre de este lugar pasa a ser también el modo en que llaman a las personas que allí se encuentran.

11 Si bien para otro contexto, Howard Becker (1971:77[1966]) señala que "una persona se sentirá libre de fumar marihuana de acuerdo con el grado en el cual llegue a considerar las concepciones convencionales sobre la droga como puntos de vista de individuos no informados, extraños a esta práctica y reemplace dichas concepciones con la visión "de adentro" que ha adquirido a través de su experiencia con la droga en compañía de otros fumadores".
}

Por último, si bien estas cosas difíciles de ingresar y de guardar son compartidas e intercambiadas, existen otro conjunto de objetos que no están destinadas al intercambio, sino que se atesoran, como veremos a continuación.

\section{Objetos que se atesoran en las piezas}

El sector es el lugar en el que los jóvenes viven en el instituto. Aquí se encuentran las piezas, baños, comedor y el patio interno o pasillo. En el sector del instituto Castelli conviven alrededor de 40 jóvenes. El mismo posee un comedor y siete habitaciones ordenadas correlativamente. Los baños y duchas se encuentran frente a las piezas y en el centro hay un patio de baldosas sobre el que se extiende a cierta altura un tejido de alambre para evitar las fugas de los internos. El instituto Malvinas tiene cuatro sectores de 10 habitaciones cada uno donde viven alrededor de 20 jóvenes. Del espacio de los sectores de los distintos institutos se ha extraído todo elemento que pueda representar "peligro" para los que ahí se encuentran o para el personal del instituto. La creencia de que "con cualquier cosa pueden hacer un arma", como me dijo una vez un trabajador social, genera en el sector un paisaje de escasez y donde se reemplazan ciertos objetos por otros: ventanas de policarbonato en lugar de vidrio, cubiertos, platos, tazas de plásticos en lugar de los tradicionales, colchones de una lana no incendiable en lugar de otros tipos de colchones. No se observan cuadros o adornos en el patio, ni sogas para colgar la ropa, por lo que la misma se extiende principalmente en las rejas de las ventanas, bancos y mesas.

A lo largo del trabajo de campo encontré diversos modos de recordar el afuera o la calle a partir de la elección de ciertos recuerdos, prácticas, objetos. Los objetos vinculados a la familia condensan ciertas memorias sobre las mismas que se quieren preservar, y por tanto no se destinan al intercambio. Como indica Kopitoff (1991: 99, 100 [1986]) "la cultura asegura que algunas cosas permanezcan inequívocamente singulares, evita la mercantilización de otras y, en ocasiones, resingulariza lo que ha sido mercantilizado". En este sentido, objetos que tienen que ver con el recuerdo de la familia y con la propia identidad en tanto hijo, hermano, padre, son guardados en los lugares más "privados" del instituto, las piezas, y llevados por los jóvenes como parte de sus pertenencias en cada traslado.

"Uno trata de tenerla lo mejor posible, es como la casa" (Daniel, agosto de 2005, inst. Malvinas).

Las cosas que los jóvenes tienen en sus piezas guardan entre sí un orden y jerarquía singular. Un día, mientras realizaba un registro fotográfico junto a un grupo de chicos del instituto Malvinas, Manuel me anunció al llegar a su pieza que allí estaba "lo más importante" y me señaló la foto de su hija en un portarretrato hecho de palitos de helado, ubicado en el centro de la repisa y junto a dos 
estampitas. De este modo, en la repisa de cada pieza o en la cabecera de las camas los chicos atesoran algunos de los objetos traídos por la visita, como fotos de la familia, elementos religiosos (estampitas, cruces, rosarios); hojas con dibujos y poemas, cartas. Se observa también con frecuencia la combinación de fotos de la familia con estampitas de santos, delimitando un espacio especial, casi sagrado.

Las piezas son compartidas por varios jóvenes que duermen en camas cuchetas o en camas comunes y en el piso. Las mismas están siempre ordenadas y limpias, siendo la limpieza la primera actividad del día que se realiza bajo la supervisión de la guardia. En contraste con otros espacios institucionales, la abundancia y diversidad de adornos e imágenes que se encuentra en las piezas es llamativa. Se colocan en las habitaciones dibujos, fotos, poemas, objetos religiosos, banderas con notable originalidad y estilo. Si bien las piezas mantienen huellas de lo institucional (rejas, ventanas pequeñas y elevadas, tarimas de cemento como camas), los jóvenes logran que tengan un tono distinto y cercano a sus gustos. En este sentido, como indica Halbwachs (2004 [1968]), las personas transforman al espacio en el que están inmersos a su imagen pero al mismo tiempo se someten y se adaptan a las cosas materiales que se le resisten.

Se dedica gran cantidad de horas de la estadía en el instituto a la decoración de las piezas. Para ello se seleccionan fotos de revistas, las cortan y pegan, y a veces les construyen marcos enrollando hojas de papel. Eligen en especial imágenes de mujeres semidesnudas, algunos autos, motos, marcas de ropa. En otras ocasiones piden afiches a los docentes para tapar aquellas paredes que están sucias o despintadas. De manera implícita está aceptado que los chicos que recién llegan puedan hacer arreglos a su gusto en la pieza que le tocó, pero en la mayoría de los casos complementan la decoración heredada de quienes estuvieron antes.

Las piezas con mayor "producción" y mejor decoradas son las preferidas por los jóvenes. Durante el registro fotográfico antes mencionado, los jóvenes quisieron sacar en primer lugar fotografías a las habitaciones que estaban mejor adornadas y a las propias, posando en ellas con orgullo y entusiasmo. Tenían mayor valor estético para ellos aquellas piezas que combinaban bien colores, poseían dibujos y pinturas en las paredes que evidenciaban una gran elaboración, presentaban una variedad de imágenes hasta llegar al techo y diseños originales.

Como se puede apreciar, los objetos asociados a la familia no se intercambian ya que su valor afectivo y simbólico los tornan inapreciables. Estos objetos permiten a los jóvenes continuar ligados a los afectos y crear un "afuera" dentro del instituto. Cuando son trasladados a otros institutos, los chicos se llevan sólo los elementos considerados más personales (fotos de familiares, poemas y cartas con su nombre, ropa) y dejan los demás (usados en la decoración de la pieza) a quienes se quedan. Asimismo, cuando la salida es definitiva, la herencia que se deja a los jóvenes que permanecen incluye toda la ropa del que se va, la cual es regalada por completo antes de dejar el instituto.

\section{Intercambios de caretas en el sector}

Careta o cara es el término utilizado por los jóvenes para referirse a los cigarrillos de tabaco que se destinan al intercambio en el sector. Si bien éstos son escasos y tienen alto valor en este lugar, ninguno de los jóvenes se preocupa por guardarlos, sino que se comparten permanentemente. Dentro de la institución se fuma gran cantidad de etiquetas de marcas económicas y sólo cuando se acaba el contenido de éstas, se recurre a tabaco suelto que viene en bolsitas. Algunos jóvenes me contaron que cuando en el sector no quedan más cigarrillos, sacan restos de tabaco de las colillas que están tiradas en el piso, y con eso fabrican un nuevo cigarrillo que fuman juntos otra vez. Los cigarrillos se consumen aquí colectivamente: cada vez que alguien enciende un cigarrillo, quienes están cerca le solicitan secas y se lo van pasando hasta que se acaba. Al contrario de lo que se podría esperar en estos espacios donde las cosas no abundan, los cigarrillos se dan como si sobrasen; ya que se entiende que si se quiere recibir, primero hay que dar y compartir.

\section{G.: - ¿Y si es el último cigarrillo que les queda, lo dan} igual?

Federico: -"Le convidás igual, si estamos todos en la misma ahí adentro, si no, cuando él tenga no le vas a poder decir nada" (Federico, instituto Malvinas, septiembre de 2005).

Quien convida una careta o da una seca, se asegura que los demás la devolverán en el momento que se pida, ya que las reglas de la reciprocidad así lo establecen. Como ya lo sugirió Mauss (1979 [1950]), existe un principio básico de intercambio que actúa de forma desinteresada y obligatoria al mismo tiempo. En este sentido, junto a la cosa que se da, se deposita un lazo que lleva a que una cosa o un favor equivalente regrese en algún momento a su dueño ${ }^{12}$. Se podría decir entonces, que a través del intercambio de cigarrillos, los jóvenes se obligan a devolver lo que se recibió y refuerzan así su relación con el grupo.

-"Siempre convidás porque si vos no tenés otra vez y le pedís a otro, te tiene que convidar porque vos le diste antes" (Daniel, instituto Malvinas, septiembre de 2006)

Cuanto más importante sea la posición del individuo, más se sentirá obligado a dar. Durante el tiempo que realicé

12 En el "potlach", el valor social y simbólico de estos intercambios se basan en una forma de obsequio que implica al mismo tiempo la obligatoriedad de restitución, con una temporalidad variable que asegura la continuidad de la relación (Mauss, 1979). 
la actividad de pasar películas ${ }^{13}$ en el comedor del sector, observé que varios chicos en distintos momentos le pedían a Alejandro cigarrillos y que éste los sacaba de sus bolsillos y convidaba. Alejandro se sentaba en el primer lugar frente al televisor y había conseguido un tacho de plástico para poner sobre el banco y ubicarse de manera más elevada que el resto. Era uno de los pocos que cambiaba los canales del televisor sin que nadie le dijera nada, y manejaba el DVD que yo llevaba para pasar las películas. Alejandro parecía ocupar un lugar importante dentro del grupo, sin embargo, esto no impedía que, cuando había una leve sospecha de que tenía cigarrillos y no los quería convidar, fuera fuertemente cuestionado.

En este sentido, como lo planteó Malinowski (2001[1922]), las personas encuentran en el dar un medio de expresión de superioridad sobre el que recibe, ya que exhibir riquezas aumenta su prestigio social. Al respecto Appadurai (1991:36 [1986]) afirma que "aunque los hombres parecen ser los agentes que definen el valor de las conchas, en realidad, sin las conchas, los hombres no podrían definir su propio valor; en este sentido, las conchas y los hombres son mutuamente agentes de la definición del valor del otro". De esta manera, el intercambio de cosas constituye la fuente de valor de quienes los intercambian, lo cual muestra una relación intrínseca entre personas y cosas que no pueden ser pensadas por separado. Por otra parte, el hecho de que además de convidarse, los cigarrillos se quemen y destruyan, indica la expresión de extrema generosidad que rodea esta acción.

"Tapiñero significa no convidar" (Lucas, junio de 2005, inst. Castelli).

En contraposición a la persona que da, el tapiñero es colocado en un lugar subalterno o desprestigiado. Se llama tapiñero al individuo que actúa de forma egoísta, dado que en lugar de compartir lo que tiene, se lo guarda para sí mismo. El tapiñero consume sus propios cigarrillos a escondidas, rompiendo la regla de solidaridad que asegura que algo escaso como el cigarrillo nunca falte en el grupo. Salvando las distancias, Malinowski (2001: 608 [1922]) encuentra que entre los Trobriandeses "ser duro en el Kula" implica actuar de manera mezquina y tardar en el intercambio: "un rasgo reconocido como reprensible y deshonroso es la tendencia a retener cierta cantidad de objetos preciosos y ser lento en pasarlos". Si observamos el sector, se considera que el tapiñero prefiere actuar por fuera de los vínculos de ayuda mutua que se tejen en este lugar, a partir de una situación común de encierro. De esta manera, quienes tienen y no comparten, no participan de la reciprocidad del grupo y carecen del capital relacional que ella genera.

Además de posibilitar que algo escaso como el cigarrillo

13 Como una excusa para poder entrar al sector (que durante gran parte de mi trabajo de campo me estuvo vedado) y brindar un poco de entretenimiento, llevé películas para ver junto a ellos en el comedor. no falte, la práctica de dar y recibir estos elementos escasos permite reforzar ciertos valores en el grupo como la generosidad y la ayuda mutua; así como también clasificar diferentes tipos de personas según sus actitudes y prácticas cercanas o no a esos valores. Por otro lado, resulta interesante reflexionar sobre la tensión continua entre lo prohibido y lo permitido que integran los sentidos de la práctica colectiva de fumar. Como observé, los gestos que acompañan el fumar tabaco en grupo dentro del instituto son semejantes al modo en que se suele fumar marihuana. Asimismo, aquellas veces que los jóvenes hablaban de "fumar" en el sector y en las piezas, no distinguían si se trataba de tabaco o marihuana. En varias oportunidades me encontré solicitándoles que aclararan a que "tipo" de fumar se referían, pero enseguida me volvían a repetir: "fumar". De este modo, lo que para mí parecía ser una distinción importante, para ellos no lo era, o al menos no consideraban necesario (o no querían) especificarla. Si bien durante mi trabajo de campo sentí muchas veces el fracaso de no poder llegar a distinciones ni clasificaciones claras, el análisis de esta cuestión me llevó a darme cuenta que era justamente la ambigüedad y las fronteras difusas lo más significativo del trabajo de campo. Al borrar las fronteras entre las prácticas permitidas y las prohibidas, los jóvenes juegan un poder y construyen una ambigüedad que actúa como resistencia a las reglas de la institución. Se produce entonces un espacio con características propias, que no se define del lado autorizado o del prohibido, sino que se encuentra en la tensión.

Cabe señalar también que son numerosos los chicos que con frecuencia no tienen cigarrillos para convidar ya que sus visitas concurren muy pocas veces al instituto. No obstante esto, ellos no resultan excluidos de las ruedas de secas, sino que son incorporados sin distinción. En el momento en que tengan nuevamente cigarrillos deberán devolverlos, y se entiende que quienes dieron siempre, tienen derecho a pedirlos. Asimismo, me encontré con algunos jóvenes que no fumaban. Aunque pocos, desde la mirada de los demás, era afortunados por no depender "del vicio" y no tener que preocuparse por la escasez de cigarrillos en el sector. Sin embargo esto no los aísla de participar indirectamente de las reglas del fumar, por ejemplo al "cubrir" a quienes prenden cigarrillos en las piezas, exponiéndose también ellos a las posibles sanciones.

Todos ellos pueden participar también de otras transacciones entre las que se encuentran el intercambiar revistas, lápices, champú, galletas, caramelos, tarjetas telefónicas, ropa y calzado. Las pertenencias de los jóvenes en el instituto se restringen a una o dos bolsas de ropa que se trasladan de un instituto a otro. Llevan allí un par de remeras, bermudas, ropa interior, un jean, algo de abrigo, ojotas, zapatillas y un toallón. De esta manera, son pocas las prendas de vestir con las que cuentan para cambiarse. Los días de mucho frío se abrigan un poco más con un buzo, campera o pantalón; o poniéndose medias con las 
ojotas, que se usan en todas las estaciones. Por otra parte, como señalé más arriba, los jóvenes guardan alguna muda especial para los días de visita, o para ir a tribunales, o para salir de permiso un fin de semana ${ }^{14}$. En este sentido, el intercambio de prendas permite variar la ropa que usan. Con frecuencia los jóvenes de una misma pieza u otros entre quienes existe confianza se prestan entre sí remeras, buzos, zapatillas que posibilitan que, en estos ámbitos caracterizados por la privación sean practicadas diversas formas de subsanar las carencias (Lomnitz, 1989).

\section{Para finalizar}

Los objetos que se intercambian, guardan, circulan en institutos correccionales de Córdoba fueron el foco desde el cual se intentó comprender el modo en que se construyen las relaciones sociales entre los jóvenes y el afuera (familia, amigos), y entre los jóvenes en el sector. En este sentido, se observaron prácticas, gestos, vínculos que se entrelazan en el dar y recibir cosas, y valores que son puestos en juego en dicha relación.

Se encontró aquí que los objetos que se regalan en la visita ayudan a mantener los lazos de afecto tanto con las personas que llegan a visitar, como con aquellas que no concurren al instituto, pero que se hacen presentes a través de las cosas que envían. El intercambio de regalos contribuye a recordar y a ser recordados por familiares y amigos, y es un medio para preservar los lazos que la distancia y el tiempo de institucionalización podrían debilitar. Asimismo, vimos que algunos objetos (fotos, poemas, cartas) son guardados en las piezas quedando al margen de cualquier transacción. Los mismos constituyen fuentes de memorias acerca de lo que implica ser hijos, hermanos, padres, personas queridas; y son parte de las posesiones que los jóvenes llevan consigo en cada traslado dentro del Sistema Correccional.

Por otra parte, los recorridos a través de los cuales se ingresan cosas al sector, permiten identificar mecanismos de visibilidad, desviación y ocultamiento que clasifican a

\footnotetext{
14 Autorización otorgada por el juzgado para salir durante el fin de semana a la casa, bajo la responsabilidad de los padres y a condición de tener que volver luego al instituto. Los permisos son dados cuando los jóvenes están próximos a salir del instituto y buscan "probar la voluntad" del joven para mantener una conducta aceptable afuera y para regresar al instituto al término del permiso. No es de extrañar que la mayor cantidad de fugas se produzcan por los no regresos de estos permisos.
}

algunas cosas como permitidas y a otras como prohibidas en el instituto. El compartir tanto unas como otras entre los jóvenes que conviven en el sector, genera una reciprocidad continua que aumenta la diversidad de las cosas que se tienen en el sector, refuerza el sentimiento de estar compartiendo "la misma situación" y jerarquiza ciertos valores al interior del grupo: generosidad, ayuda mutua, compartir riesgos.

De esta manera, dentro de ámbitos institucionales caracterizados por la privación y la escasez, es posible observar una diversidad de modos de intercambiar y compartir que, combinados con la ambigüedad y la complicidad dentro del grupo, le dan nuevos sentidos a la abundancia y el poder.

\section{Bibliografía}

Reguillo Cruz, R. 2000 Emergencia de culturas juveniles. Estrategias del desencanto. Ed. Norma, Buenos Aires

Halbwachs, M. 2004 [1968] La memoria colectiva. Prensas Universitarias de Zaragoza, Zaragoza

Appadurai, A. 1991 [1986] Introducción. En La vida social de las cosas, editado por A. Appadurai, pgs17-87, Editorial Grijalbo, México

Becker, H. 1971 [1966] Los extraños. Sociología de la desviación. Tiempo Contemporáneo, Buenos Aires

Kopytoff, I. 1991 [1986] La biografía cultural de las cosas: La mercantilización como proceso. En La vida social de las cosas, editado por A. Appadurai, 89- 122, Editorial Grijalbo, México

Lommitz, L. 1989 ¿Cómo sobreviven los marginados?. Siglo XXI editores, México

Malinowski, B. 2001 [1922] Los argonautas del pacífico occidental. Península, Barcelona.

Mauss, M. 1979 [1950] Sociología y Antropología. Tecnos, Madrid

Morton, C. 2007 Remembering the House: Memory and Materiality in Northern Botswana. Journal of Material Culture, Vol 12(2): 157-179 